\title{
Cartografía de inundaciones en la planificación territorial. Estudio comparado entre Argentina y España
}

\section{Flood mapping in land use planning: a comparative study between Argentina and Spain}

\author{
Paula Andrea Zapperi (1) y Jorge Olcina² (1)
}

\begin{abstract}
RESUMEN
La gestión del riesgo de inundación ha cobrado nuevo protagonismo gracias a la incorporación de las herramientas cartográficas en la planificación territorial. La elaboración de mapas de riesgo de inundación se asumió en diversos países como una pieza importante en la planificación de nuevos usos en el suelo. De manera que las medidas tradicionales de reducción del riesgo de inundación basadas en actuaciones estructurales sobre el territorio se han enriquecido con la incorporación de la cartografía de riesgo como argumento de acreditación jurídica en la ordenación del territorio. Este trabajo analiza la aplicación de cartografía de riesgo de inundación en la planificación territorial de Argentina y España. El análisis se focalizó la utilización de documentos cartográficos para acreditar niveles de riesgos en la escala local. Se identificó que ambos países han apostado por la elaboración de cartografía de riesgo en los procesos de asignación de nuevos usos en el suelo, si bien los resultados de su implementación difieren según la existencia de normativa. Se comprueba para España y la Argentina que en los procesos urbanísticos el mapa de inundaciones se entiende como mapa de peligrosidad, sin integrar, salvo ejemplos puntuales, análisis de vulnerabilidad en los territorios objeto de planificación.
\end{abstract}

Palabras clave: Riesgo de inundación, Cartografía, Planificación territorial, Argentina, España.

\begin{abstract}
Flood risk management has gained new prominence thanks to the incorporation of cartographic tools in spatial planning. Flood risk mapping has been incorporated in several countries as an important piece when it comes to planning new land uses. Thus, traditional flood risk reduction measures based on structural measures have been enriched with the incorporation of risk mapping as an argument for legal accreditation in land use planning. This paper analyzes the application of flood risk mapping in land use planning in Argentina and Spain. The analysis is focused on the use of cartographic documents to certify risk levels at a local scale. These are two countries that have opted for the elaboration of risk mapping in the processes of assigning land uses. Although the results of their implementation are different in relation to the existence of regulatory regulations for these processes and the different administrative scales with competences in spatial planning and urban planning. In both cases, it is verified that the flood map in urban processes is understood as a hazard map, without integrating, except for specific examples, vulnerability analysis in the territories under planning.
\end{abstract}

Keywords: Flood risk, Cartography, Spatial planning, Argentina, Spain. 
Las inundaciones constituyen uno de los peligros climáticos de mayor perjuicio para los espacios urbanos. Esta tendencia lejos está de revertirse ante un panorama de cambio en los patrones de lluvia e intensificación de eventos hidrometeorológicos extremos (JRC, 2017). Al mismo tiempo, el crecimiento poblacional incrementa la ocupación de espacios inundables. Ya sea a través de la extensión de asentamientos informales (De Mattos, 2010) o de la revalorización de áreas para la urbanización a partir de la ejecución de obras hidráulicas que generan sensación de falsa seguridad (Koks et al., 2015; Rojas et al., 2017). Estas intervenciones llevan a que población con bajos niveles de vulnerabilidad quede expuesta a pulsos naturales de inundación cuyos efectos pueden agravarse en respuesta a las intervenciones realizadas (White et al., 2001; Ollero, 2015). Esto permite entender al riesgo como un proceso de construcción histórica, social y territorial a través de la articulación entre amenazas y vulnerabilidades (Cardona, 2003). De esta manera, su análisis se estructura en función de las nociones de peligrosidad, vulnerabilidad, exposición, teniendo en cuenta que el riesgo es siempre probabilidad de ocurrencia y contiene un grado de incertidumbre que intenta cuantificar dicho análisis (Ayala-Carcedo, 2000; Calvo García-Tornel, 2001; Ribas \& Saurí, 2006, Ríos \& Natenzon, 2015).

Bajo esta perspectiva y trasladando los principios de la Gestión Integral del Riesgo de Desastre (GIRD) al riesgo de inundación, la restricción de la ocupación de áreas de riesgo puede limitar las consecuencias reales de las inundaciones en un territorio. Al mismo tiempo que los códigos de construcción pueden incorporar medidas que contribuyan a que ciertas estructuras resistan a eventos de inundación con daños mínimos. De este modo, la ordenación de los territorios puede prevenir el aumento del riesgo de inundación, a través de controles activos sobre desarrollo de tierras y propiedades en estas áreas (Hooijer et al., 2004). La definición de umbrales de peligrosidad y su consideración para regir la ocupación son fundamentales en la organización de los usos y las actividades expuestas (Merz et al., 2010).

La ordenación sostenible de los territorios es una obligación ética de las administraciones encargadas de la gestión ambiental y socioeconómica. Además, se ha convertido en una exigencia para la consecución de los Objetivos de Desarrollo Sostenible de las Naciones Unidas (2015), en un contexto, además, de cambio climático. En la actualidad la ordenación del territorio enfrenta retos en el marco de la sostenibilidad como principio rector de las actuaciones planificadas: 1) debe considerar los recursos y los riesgos del medio físico; 2) debe incorporar las normativas ambientales emanadas por las administraciones competentes: 3) debe cumplir la jerarquía de las escalas de trabajo que son fundamentales en la práctica jurídica; y 4) debe incorporar una fase de diagnóstico continuado a partir del diseño de indicadores de seguimiento para la evaluación continua de los planes. Y todo ello bajo el principio de la transparencia y la información en abierto a la sociedad por parte de las administraciones competentes (Olcina Cantos, 2009).

El mapa es, por tanto, un elemento fundamental para incorporar el riesgo natural en los procesos de planificación territorial. Todo plan de ordenación territorial, a cualquier escala y especialmente en la escala urbana, debe contener cartografía bien elaborada sobre peligrosidad y vulnerabilidad ante un peligro. En muchos países, el mapa se ha convertido en el documento de acreditación legal de la condición de riesgo de un territorio objeto de planificación, puesto que la obligación de elaborar este instrumento cartográfico se ha incluido en las leyes del suelo y ordenación territorial. Un mapa de riesgo de inundación es un documento clave para la clasificación 
urbanística, de ahí que su elaboración requiera precisión y detalle. No es un mapa de peligrosidad, como ha sido habitual elaborar en los análisis del riesgo con finalidad urbanística; el mapa de riesgo incluye peligrosidad y agrega la vulnerabilidad social, económica y patrimonial (Perles Roselló \& Cantarero Prados, 2010). La escala de elaboración debe adaptarse a las tramas urbanas y para ello es necesario, además de ajustes cartográficos, la realización de trabajo de campo para confirmar los resultados que ofrecen los portales cartográficos de las administraciones (Olcina Cantos \& Díez Herrero, 2017). Las administraciones competentes en materia urbanística deben velar porque los mapas de riesgo natural que acompañen los documentos de planeamiento urbanístico estén elaborados con los criterios de rigor y en la escala idónea para el espacio geográfico objeto de transformación (González García, 2009).

\section{Inundaciones urbanas: eventos decisivos en la gestión del riesgo en Argentina y España}

En la Argentina se estima que una de cada tres personas vive en áreas altamente expuestas a inundaciones, lo que implica un total de 14,2 millones de personas en todo el país (Swiss Re, 2016). Las inundaciones ligadas a los valles de los grandes ríos de la cuenca del Plata se destacan a nivel nacional de acuerdo a su duración y grado de afectación. En dicha región se genera más del 76"\% del PIB nacional y se ubica el 70"\% de la población (Bertoni, 2004). Esta disposición se ve acentuada, a su vez, por la tendencia expansiva de las periferias de las ciudades como parte del crecimiento de los núcleos urbanos intermedios (Ministerio de Planificación Federal, Inversión Pública y Servicios, 2011). Asimismo, el contexto de cambio climático que aporta cambios significativos en la ocurrencia de eventos extremos de precipitación (Barros et al., 2015) se conjuga con la ocupación de sectores ribereños y llanuras de inundación produciendo un aumento en la frecuencia de inundaciones urbanas.

El número de víctimas fatales en las inundaciones de las ciudades de Santa Fe y La Plata constituyen casos emblemáticos en la historia argentina. En el año 2003 la crecida del río Salado del Norte (tributario del Paraná) provocó en la ciudad de Santa Fe la muerte de 152 personas y 130.000 habitantes debieron ser evacuados. Este desastre instaló a nivel nacional el cuestionamiento sobre la habilitación de áreas inundables para su incorporación a la ciudad. A la vez que puso en evidencia la importancia de las políticas urbanas orientadas a evitar la generación de condiciones de riesgo (Viand \& Gonzalez, 2012). Diez años más tarde, el día 2 de abril en la ciudad de La Plata una precipitación de $300 \mathrm{~mm}$ en tres horas derivó en 89 víctimas fatales (Plan de Reducción de Riesgo por Inundaciones La Plata, 2019).

Si bien la respuesta gubernamental argentina ha priorizado la adopción de medidas estructurales y la atención de la emergencia, en los últimos años se han generado iniciativas en favor de una gestión integrada de los riesgos naturales (González, 2018). En la elaboración del Plan Estratégico Territorial 1816-2016, a cargo del entonces Ministerio de Planificación Federal, el diagnóstico de las distintas regiones del país consideró la existencia de peligros naturales manifestando la idea que supone a la acción sobre el territorio como una estrategia de prevención temprana del riesgo de desastre. En este marco, la sanción de la Ley 27287/16 para la creación del Sistema Nacional para la Gestión Integral del Riesgo y la Protección Civil (SINAGIR) implicó un avance en los esfuerzos de integración con la planificación del territorio y por ende en la iniciativa de elaboración de cartografía. 
En España, se ha calculado que 977.000 personas viven en zonas de inundación para un período de retorno de 500 años (Observatorio de la Sostenibilidad, 2019). Las superficies artificiales situadas en áreas con riesgo de inundación se han calculado en 26.863 ha para dicho período de retorno. Por su parte, según este estudio los daños provocados por las inundaciones podrían elevarse a $\mathbf{2 0 . 0 0 0}$ millones de euros anuales en la década de 2020, a 46.000 millones de euros anuales en la década de 2050 y a 98.000 millones de euros anuales en la década de 2080. La peligrosidad ante las inundaciones ha pasado de ser una cuestión de llanuras de inundación de grandes colectores fluviales, a convertirse en un problema en cuencas pequeñas con un grado elevado de ocupación humana en sus tramos medios y finales. Esto afecta fundamentalmente a espacios urbanos de la fachada mediterránea, del País Vasco y del archipiélago canario -Gran Canaria y Tenerife-. Es en estos "espacios de riesgo" donde se concentran las pérdidas más importantes en términos económicos y de vidas humanas (Gil-Guirado et al., 2014). Ello es debido a la acumulación de población y actividades en el medio urbano ( $80 \%$ de la población total en España en 2019) y a la deficiente planificación urbana que no ha tenido en cuenta la ocurrencia de las inundaciones y sus efectos territoriales en los procesos de asignación de usos en el suelo (Ribas et al., 2020).

El desastre del camping de Biescas (Pirineo aragonés), ocurrido en agosto de 1996, derivó en efectos políticos que contribuyeron con la generación de un consenso generalizado en que la planificación del territorio es la medida preventiva más sostenible, adaptativa y económicamente rentable en la mitigación de las pérdidas causadas por inundaciones. En este contexto la aprobación de la Ley del Suelo de 2008 abrió un proceso lógico, de acuerdo a lo desarrollado en otros países europeos, para la utilización de la ordenación territorial como herramienta jurídico-administrativa de reducción del riesgo natural. Frente a la anterior Ley del Suelo de 1998, que en este aspecto se incumplió sistemáticamente al no señalar el procedimiento necesario para la clasificación de un suelo como no urbanizable cuando existiera "riesgo natural acreditado", la ley de 2008 (y texto modificado de 2015) obligaba a la elaboración de mapas de riesgos naturales. Asimismo, a ello se ha unido la mejora en la normativa de aguas que contiene preceptos que afectan a la planificación territorial y urbana. En España la clasificación de un espacio geográfico como "área inundable" dependía de una medida hidráulica. Sin embargo, la modificación de Reglamento de Dominio Público Hidráulico a través del RD 638/2016 implicó la incorporación de aspectos relacionados al riesgo de inundaciones en la planificación territorial (Perles, Olcina \& Mérida, 2018).

Corresponde al ser humano conocer los territorios donde implantará usos y actividades y ello supone la obligación de análisis detallados del riesgo de inundaciones existente en ellos. Si no se hace, por desconocimiento o acción premeditada, los efectos ocasionados por un episodio natural de rango extraordinario no pueden ser imputables a la naturaleza, como ha sido habitual en España durante décadas. Ante un escenario de clima cambiante y con un posible incremento de eventos atmosféricos extremos, la reducción del riesgo frente a los riesgos climáticos debe pasar por la aplicación de medidas de reducción de la exposición y de la vulnerabilidad (Barton \& Irarrázabal, 2016). A pesar de las diferencias históricas, políticas y geográficas entre ambos países es la materialización de la amenaza y por ende la ocurrencia de inundaciones lo que ha llevado a buscar en la planificación territorial herramientas para detener $\mathrm{o}$, al menos, atenuar la construcción de "espacios de riesgo".

Aunque Argentina puso en marcha los sistemas de gestión de las emergencias -protección civil- en fecha más temprana (1939) que en España (1982), es cierto que las coyunturas políticas 
y económicas en la segunda mitad del siglo XX, ha favorecido que las acciones de gestión del riesgo hayan tenido un impulso mayor en España, especialmente desde su ingreso en la Unión Europea y la incorporación, a su normativa, de las directivas sobre seguridad y gestión del riesgo emitidas por la institución europea. No obstante, en el marco de los acuerdos internacionales de reducción de riesgos de desastre (DIRDN, 1990-99, EIRDN, 2000, Marco de Acción de Hyogo, 2005-2012 y Marco de Sendai, 2015-30), la colaboración entre ambos países ha sido estrecha. En la actualidad, ambos países, con sus diferencias normativas, comparten una visión común para la gestión de los riesgos naturales, basada en los sistemas de gestión integral. De manera que el riesgo de inundación, planificado hasta el 2000 básicamente como reducción a partir de la obra civil, ha ampliado sus acciones con medidas de ordenación territorial, cartografía de riesgo y gestión de las emergencias, con el ánimo de cubrir todas las etapas de un proceso de desastre (pre-evento, evento y post-evento).

La pregunta que guía esta investigación es conocer la concepción de riesgo que predomina en la elaboración de mapas de inundación orientados a dirigir la habilitación nuevos espacios urbanos como también en aquellos ya consolidados. La idea de su realización surge a raíz de una estancia de investigación de la autora de este trabajo en la Universidad de Alicante, cuyo Instituto Interuniversitario de Geografía se ha especializado en la planificación y gestión de los riesgos naturales y su incorporación en los procesos de ordenación territorial, a diversa escala. Del análisis de la realidad existente en ambos países, se pretende conocer:

- Concepciones del análisis de riesgo en la planificación territorial en ambos países;

- Elaboración de cartografía de riesgo incorporado en los planes territoriales, a diversa escala;

- Grado de cumplimiento de la normativa urbanística y territorial existente en ambos países en relación con la incorporación de los análisis del riesgo de inundaciones y de la cartografía correspondiente en los documentos de ordenación territorial;

- Conclusiones sobre buenas prácticas que puedan compartirse en ambos países.

El objetivo específico del trabajo es analizar la aplicación de cartografía de riesgo de inundación en la planificación territorial de Argentina y España bajo una perspectiva de análisis comparado. El interés se fundamenta en el papel que han adquirido los mapas de riesgo como documentos de acreditación del grado de riego en los espacios objeto de planificación territorial. La comparación propuesta se fundamenta en la posibilidad de identificar similitudes y diferencias en cuanto a los criterios de elaboración e implementación de mapas de inundación en la gestión del crecimiento de las ciudades. Se pretende aportar reflexión y sugerencias que contribuyan con la incorporación del mapa como documento de valor operativo para el manejo y prevención del riesgo de inundación en la escala local.

\section{Material y Métodos}

Para identificar la implementación de mapas de riesgo de inundación en el marco de procesos de planificación territorial se realizó una revisión de aquellos documentos que incluyen preceptos que impulsen u obliguen su elaboración. Este tipo de revisión ha sido empleada en el marco de investigaciones que exploran la integración del riesgo de inundación en procesos de ordenación 
territorial (Olcina et al., 2016; Ran \& Nevodic-Budic, 2017; Penning-Rowsell \& Becker, 2019). El análisis se focalizó en la utilización de documentos cartográficos para acreditar niveles de riesgos, básicamente en la escala local. Se consideraron casos significativos en que sus características hidrogeomorfológicas han presentado históricamente inundaciones. Las referencias sobre el requerimiento de este tipo de mapas se consideraron como un indicador que permite evaluar positivamente la integración de este tipo de cartografía con la planificación espacial (Figura №1).

Figura $\mathrm{N}^{\circ} 1$.

Aspectos básicos en el análisis de riesgos naturales

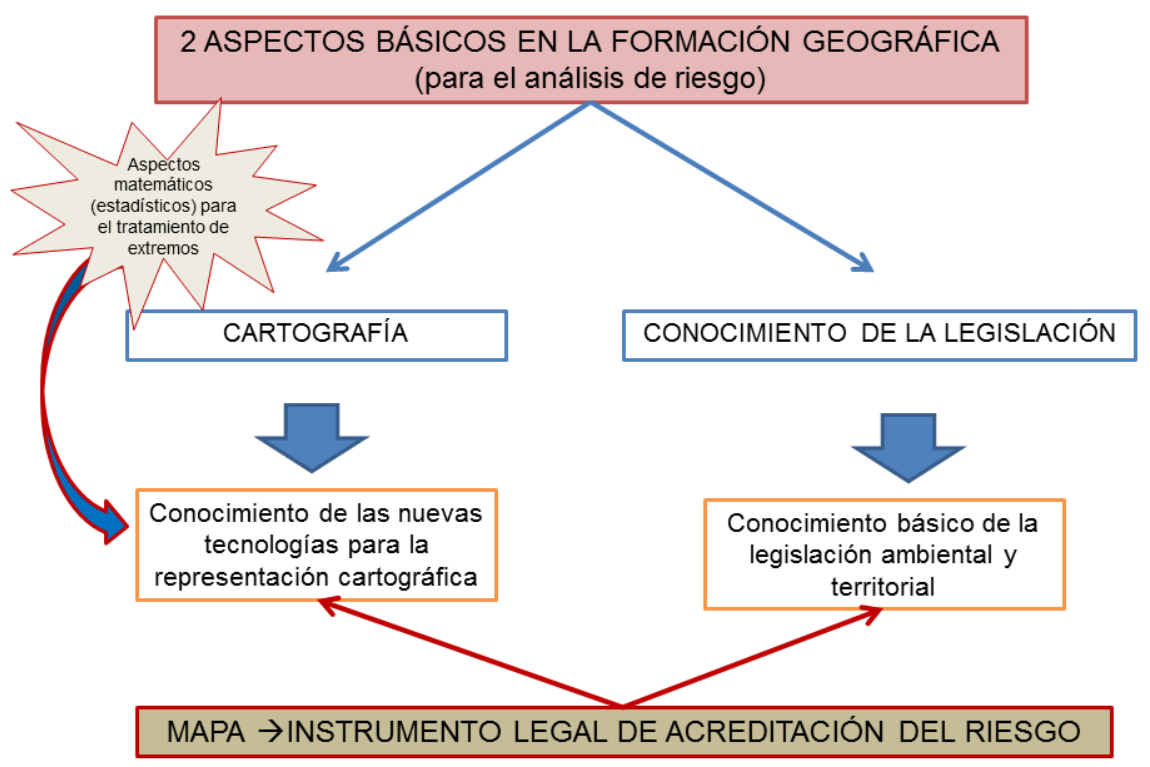

Fuente: Elaboración propia.

En lo que respecta a la revisión específica de la cartografía se consideró la categorización propuesta de Olcina Cantos y Díez Herrero (2017) lo que permitió a su vez estructurar el análisis comparativo. Esta clasificación a su vez muestra la evolución de la concepción del fenómeno de inundación y los productos cartográficos resultantes (Cuadro $\mathrm{N}^{\circ} 1$ ). Mientras en sus inicios los mapas presentaban las zonas afectadas en la actualidad constituyen documentos síntesis que integra peligrosidad y vulnerabilidad en los que se establecen niveles de riesgos según el grado de exposición.

Sin olvidar la importancia del conocimiento de las escalas administrativas en los procesos de ordenación territorial, el presente trabajo aborda su análisis en la escala local, que es la más próxima al ciudadano y la que muestra efectos más directos de las decisiones adoptadas en los documentos de planificación. La escala local, a través de sus documentos de planificación urbanística, debe incorporar las determinaciones de las normativas y planes de escala superior (regional, estatal o supraestatal) en materia de reducción del riesgo natural y debe elaborar cartografía de detalle, que resulta básica para la asignación de nuevos usos en el suelo. 
Cuadro $\mathrm{N}^{\circ} 1$.

Evolución de la concepción del riesgo de inundación y productos cartográficos asociados

\begin{tabular}{|c|c|c|c|c|}
\hline \multirow{3}{*}{ CRONOLOGÍA } & \multicolumn{2}{|c|}{$\begin{array}{c}\text { PRODUCTO } \\
\text { CARTOGRÁFICO }\end{array}$} & \multirow{2}{*}{\multicolumn{2}{|c|}{$\begin{array}{c}\text { CONSIDERACIÓN DE LAS } \\
\text { INUNDACIONES POR PARTE DE } \\
\text { ADMINISTRACIÓN }\end{array}$}} \\
\hline & \multirow[b]{2}{*}{ España } & \multirow[b]{2}{*}{ Argentina } & & \\
\hline & & & Fenómeno & $\begin{array}{l}\text { Visión del } \\
\text { mapa }\end{array}$ \\
\hline $\begin{array}{c}\text { s. XVI a finales del } \\
\text { s. XVIII }\end{array}$ & $\begin{array}{l}\text { Cartografías } \\
\text { indirectas }\end{array}$ & -- & $\begin{array}{c}\text { Inevitable } \\
\text { Excepcional }\end{array}$ & $\begin{array}{l}\text { Documento } \\
\text { informativo }\end{array}$ \\
\hline $\begin{array}{l}\text { Finales s. XVIII } \\
\text { a mediados del } \\
\text { s. XX }\end{array}$ & $\begin{array}{l}\text { Mapas de zonas } \\
\text { afectadas } \\
\text { (Mapas de } \\
\text { Calamidad) } \\
\end{array}$ & -- & Extraordinario & $\begin{array}{l}\text { sobre áreas } \\
\text { afectadas }\end{array}$ \\
\hline $2^{a}$ mitad s. XX & $\begin{array}{c}\text { Mapas de } \\
\text { inundabilidad y } \\
\text { peligrosidad por } \\
\text { inundaciones }\end{array}$ & $\begin{array}{c}\text { Cartas de } \\
\text { Peligrosidad } \\
\text { Geológica } \\
\text { ( 1:250.000) } \\
\text { Mapas de } \\
\text { inundabilidad } \\
\text { (Delimitación de la } \\
\text { línea de ribera) }\end{array}$ & Imprevisible & $\begin{array}{l}\text { Documento } \\
\text { técnico para } \\
\text { la adopción } \\
\text { de medidas } \\
\text { estructurales }\end{array}$ \\
\hline Siglo XXI & $\begin{array}{l}\text { Mapas de riesgo } \\
\text { de inundación } \\
\text { (Análisis de } \\
\text { peligrosidad y } \\
\text { vulnerabilidad. } \\
\text { Establecimiento de } \\
\text { niveles de riesgo } \\
\text { según el grado de } \\
\text { exposición) }\end{array}$ & $\begin{array}{c}\text { Manual para la } \\
\text { elaboración de } \\
\text { Mapas de Riesgo } \\
\text { (Aplicado a la } \\
\text { gestión integral } \\
\text { del riesgo y la } \\
\text { protección civil } \\
\text { de los gobiernos } \\
\text { locales) }\end{array}$ & $\begin{array}{c}\text { Previsible. } \\
\text { Consustancial } \\
\text { con la dinámica } \\
\text { natural }\end{array}$ & $\begin{array}{c}\text { Documento } \\
\text { operativo para } \\
\text { la planificación } \\
\text { territorial }\end{array}$ \\
\hline
\end{tabular}

Fuente: Elaboración propia sobre la base de Olcina Cantos \& Díez Herrero (2017).

\section{La integración interinstitucional define las bases de la gestión del riesgo en Argentina}

En el año 2012 el Consejo Federal de Planificación y Ordenamiento Territorial (COFEPLAN) presentó el Anteproyecto de Ley Nacional de Ordenamiento Territorial el cual enfatiza la articulación de las políticas regionales y locales en las fases de preparación, respuesta y recuperación en el marco de la gestión integral del riesgo. En el año 2016, la creación del Sistema Nacional de Gestión del Riesgo (SINAGIR) (Ley 27287/16) conformó un antecedente fundamental en la consideración del mapa de riesgo como un instrumento de gestión. En este marco, la concepción de riesgo como integración de factores de peligrosidad y vulnerabilidad se trasladó también al Plan Nacional de Reducción del Riesgo de Desastres 2018-2023 (PNRD 2018-2023) a cargo de la Secretaría de Protección Civil (Ministerio de Seguridad de la Nación). En cuanto a la labor cartográfica, se inicia también en este período el desarrollo de mapas interoperables que permitan la actualización diaria del grado de afectación a diferentes escalas espaciales. Este formato también se propone para la visualización permanente de informes y cartografía socioambiental sobre determinadas cuencas hídricas. Al mismo tiempo que se busca el desarrollo de cartas topográficas de peligrosidad por inundaciones teniendo en cuenta propiedades hidrogeomorfológicas. 


\section{El mapa de riesgo como herramienta de gestión a nivel local}

Según el Plan Operativo del SINAGIR el estado municipal conforma la primera instancia de reacción ante la ocurrencia de eventos adversos. Frente a esta formulación, se promueve que los gobiernos locales cuenten con un mapa de riesgo. Por consiguiente, desde la Secretaría de Protección Civil y Abordaje Integral de Emergencias y Catástrofes se ha publicado el Manual para la elaboración de Mapas de Riesgo para brindar bases metodológicas al proceso de armado de documentos cartográficos que respondan a las "necesidades básicas de planeamiento" (Ministerio de Seguridad, 2017).

Esta iniciativa buscó conformar un equipo nacional con un mismo lenguaje conceptual y metodológico en la elaboración de mapas de riesgo que a través del análisis de amenazas y factores de vulnerabilidad permitan el planteo de áreas críticas y escenarios de riesgo. Si bien se busca que los resultados cartográficos sirvan de insumo para propuestas de zonificación, aún no existen casos concretos de su aplicación en procesos de diagnóstico para la asignación de usos en ámbitos urbanos. No obstante, tal como se menciona en el Cuadro $\mathrm{N}^{\circ} 2$, ya se presentan casos de gobiernos locales que han incorporado en sus municipios mapas de inundación en el marco del SINAGIR.

Cuadro $\mathrm{N}^{\circ} 2$.

Cartografía de riesgo de inundación en Argentina según objetivo de aplicación

\begin{tabular}{|c|c|c|c|}
\hline $\begin{array}{l}\text { OBJETIVO DE } \\
\text { APLICACIÓN }\end{array}$ & $\begin{array}{l}\text { CARTOGRAFÍA } \\
\text { DE RIESGO DE } \\
\text { INUNDACIÓN } \\
\text { EXISTENTE } \\
\end{array}$ & $\begin{array}{c}\text { ESCALAS DE } \\
\text { INTERACCIÓN } \\
\text { INSTITUCIONAL }\end{array}$ & $\begin{array}{c}\text { VARIABLES } \\
\text { CARTOGRAFIADAS }\end{array}$ \\
\hline \multirow[t]{2}{*}{$\begin{array}{l}\text { Elaboración de me- } \\
\text { didas de preven- } \\
\text { ción, mitigación y } \\
\text { planes de contin- } \\
\text { gencia antes de } \\
\text { inundaciones }\end{array}$} & \multirow{2}{*}{$\begin{array}{l}\text { Cartografía de Riesgo en } \\
\text { el marco del SIRAGIR - } \\
\text { Ley } 27287 / 16 \text { - } \\
\text { (Ejemplos: ciudad de Ro- } \\
\text { sario; localidad del Chal- } \\
\text { tén) } \\
\text { Cartografía del Plan de } \\
\text { Reducción de Riesgo por } \\
\text { Inundaciones (RRI) para } \\
\text { la región de La Plata }\end{array}$} & $\begin{array}{l}\text { ESTATAL (Secretaría } \\
\text { de Protección Civil y } \\
\text { Abordaje Integral de } \\
\text { Catástrofes y Emer- } \\
\text { gencias) - } \\
\text { LOCAL (Defensa Civil } \\
\text { en los municipios) }\end{array}$ & \multirow{2}{*}{$\begin{array}{l}\text { - Niveles de riesgo en } \\
\text { función de los nive- } \\
\text { les de vulnerabilidad y } \\
\text { amenaza. } \\
\text { - Localización de insta- } \\
\text { laciones críticas duran- } \\
\text { te la emergencia }\end{array}$} \\
\hline & & $\begin{array}{l}\text { ESTATAL (Universidad } \\
\text { Nacional de La Plata) } \\
\text { - LOCAL (Municipio } \\
\text { de La Plata) }\end{array}$ & \\
\hline $\begin{array}{l}\text { Asignaciones de } \\
\text { uso en función del } \\
\text { riesgo de inunda- } \\
\text { ción }\end{array}$ & $\begin{array}{l}\text { Cartografía de Zonifica- } \\
\text { ción de riesgo hídrico } \\
\text { del AMGR por crecida } \\
\text { de ríos y por precipita- } \\
\text { ciones } \\
\text { (Resolución } 121 / 14 \text { ) } \\
\text { (Resolución } 303 / 17 \text { ) }\end{array}$ & $\begin{array}{l}\text { PROVINCIAL (Admi- } \\
\text { nistración Provincial } \\
\text { de Agua) - LOCAL } \\
\text { (Municipio de Resis- } \\
\text { tencia) }\end{array}$ & $\begin{array}{l}\text { - Zonificación del riesgo } \\
\text { hídrico para restriccio- } \\
\text { nes de uso según línea } \\
\text { de ribera. } \\
\text { - Zonificación del riesgo } \\
\text { hídrico por tormentas } \\
\text { severas (escurrimientos } \\
\text { naturales y artificiales, } \\
\text { tiempo de retorno de } \\
\text { las lluvias, sistemas de } \\
\text { desagües pluviales). }\end{array}$ \\
\hline
\end{tabular}

Fuente: Elaboración propia.

Paralelamente, se están llevando a cabo otras iniciativas que integran aspectos inherentes a la peligrosidad y a la vulnerabilidad. Se destaca el Plan de Reducción de Riesgo por Inundaciones 
(RRI) para la región de La Plata, publicado en octubre de 2019 como producto de un convenio entre la Universidad Nacional de La Plata (UNLP) y el gobierno local. Su principal objetivo es definir protocolos de actuación ante eventos de tormentas severas tanto a escala de cuenca urbana como también de cada barrio de la ciudad. En la Figura $\mathrm{N}^{\circ} 2$ se presenta el mapa de riesgo de inundación que resulta de la integración los mapas de vulnerabilidad y peligrosidad elaborados para el ámbito urbano y rural. Si bien no recibe una implementación concreta por parte de regulaciones de uso, pretende ser un antecedente para la elaboración de normativa de ocupación territorial.

Figura $\mathrm{N}^{\circ} 2$.

Mapa de riesgo por inundación del partido de La Plata
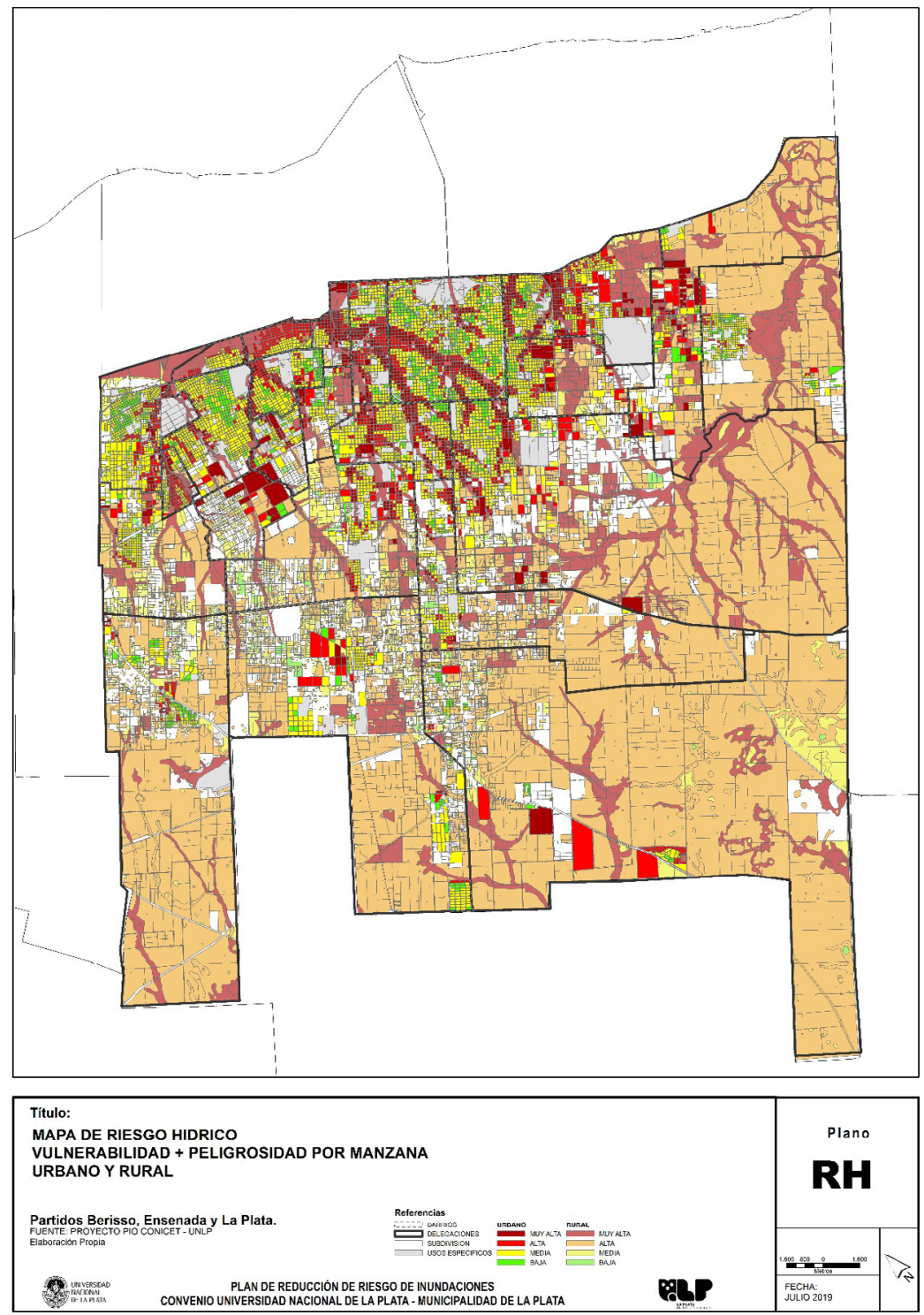

Fuente: Plan de Reducción de Riesgo por Inundaciones La Plata (2019). 


\section{Restricción de usos en función de la peligrosidad}

Desde el punto de vista de las restricciones de la ocupación de áreas bajo riesgo de inundación, se puede mencionar la Ley 11730/00 (Decreto reglamentario 3695/03) de la provincia de Santa Fe que regula el régimen de uso de bienes situados en las áreas inundables. En el caso de la ciudad capital, el desastre del año 2003 llevó a la zonificación de áreas inundables y de seguridad hídrica a través del Código de Ordenamiento Urbano (Ordenanza 11748/10). Sin embargo, es de destacar que estas restricciones de uso no encuentran su correspondencia con cartografía de riesgo elaborada para fines de planificación territorial.

Por otra parte, la implementación de restricciones en el Área Metropolitana del Gran Resistencia (AMGR), provincia del Chaco, constituye un caso pionero en cuanto a regulaciones del uso del suelo por riesgo de inundación. Esta aglomeración urbana se dispone sobre la llanura de inundación del río Paraná ocupando también las riberas de sus brazos y afluentes. En el año 1966 la construcción de un anillo de defensa inició un período de ejecución de obras de defensa. Sin embargo, los reiterados episodios de crecidas y lluvias intensas obligaron la implementación de ordenanzas basadas en resoluciones de la Administración Provincial del Agua (APA) (Rohrmann \& Schaller, 2016). Con el establecimiento de las líneas de ribera de los ríos del sector, se recomendó a los municipios del AMGR adecuar la zonificación de usos del suelo.

En el año 2017 se publicó la cartografía que respalda las restricciones de la Resolución 303/17 para el AMGR definidas según las crecidas de los ríos Negro, Salado y el canal Soberanía Nacional. En este caso el riesgo hídrico también fue obtenido en función de la línea de ribera según distintos períodos de retorno. Por lo que la restricción severa resulta de crecidas estimadas con tiempo de recurrencia de 20 años y las áreas de con restricción leve o parcial se dan los sectores topográficamente superiores a las cotas hidrométricas asociadas a crecidas con tiempo de recurrencia de 100 años (Figura $N^{\circ} 3$ ). A la cartografía de riesgo hídrico focalizada en la dinámica fluvial se suma la zonificación de riesgo hídrico ante precipitaciones (Resolución 121/14). Se considera que los escurrimientos naturales y artificiales y las restricciones de la cartografía derivan del tiempo de retorno de las lluvias y de la existencia de sistemas de desagües pluviales o su proyección. Sin embargo, en los asentamientos del AMGR que continúan anegándose periódicamente por lluvias existen otros factores también claves en la generación de anegamientos que quedan fuera de una delimitación del riesgo que considera los factores que hacen a la peligrosidad. En este caso se trata de carencia de cloacas, precariedad habitacional y los basurales espontáneos a cielo abierto (Alcalá \& Rus, 2017). Precisamente aspectos que otorgan vulnerabilidad, pero a su vez sobre los cuales se pueden implementar acciones de remediación. 
Figura $\mathrm{N}^{\circ} 3$.

Zonificación de riesgo hídrico del Área Metropolitana del Gran Resistencia por crecida de ríos

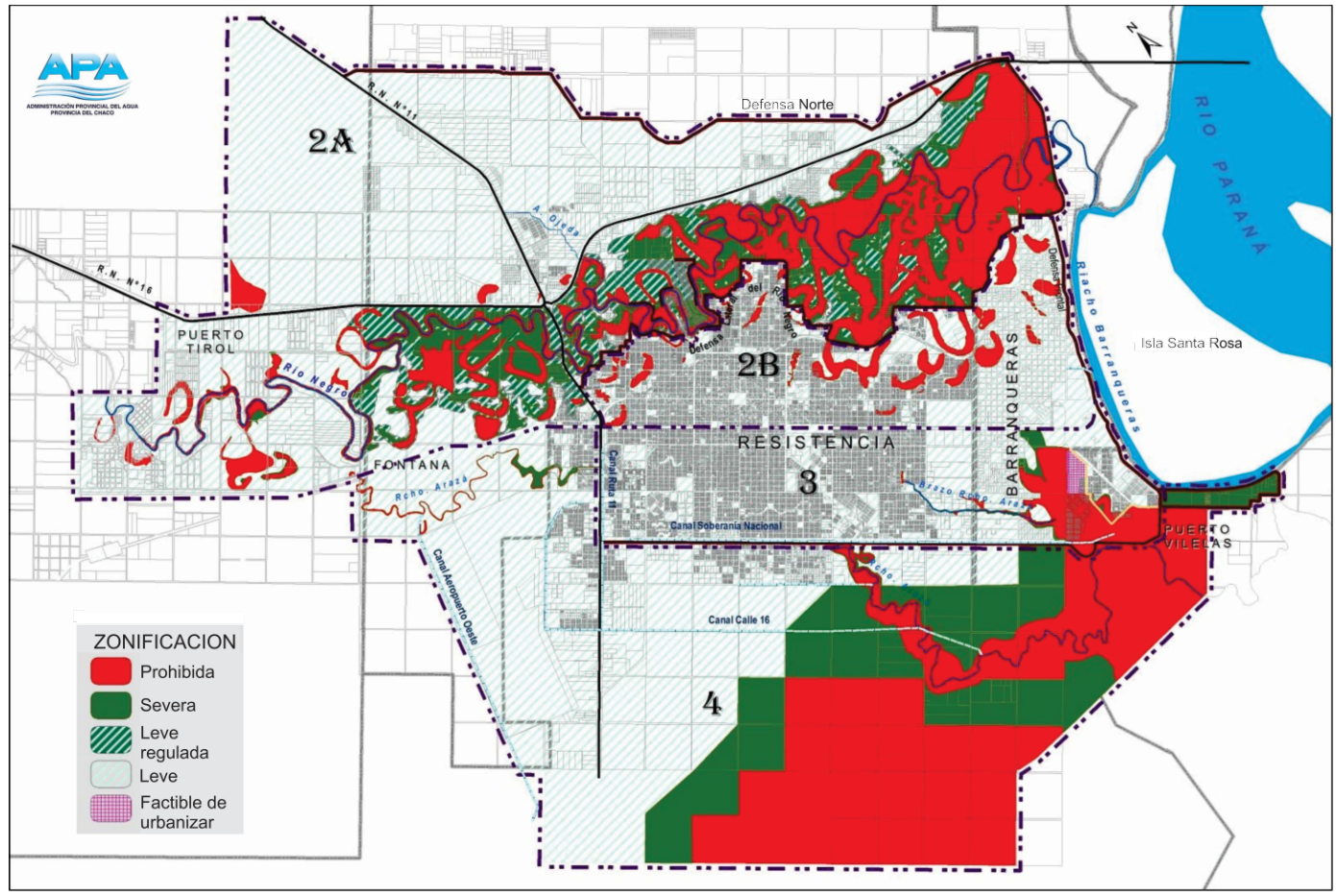

Fuente: Administración Provincial de Aguas de la provincia del Chaco (2017)

\section{Incorporación de la cartografía de riesgo en los procesos de ordenación urbana en España}

La Directiva de evaluación y gestión de los riesgos de inundación (60/2007) de la Unión Europea contribuyó en España de modo decisivo a la consideración de la ordenación territorial como herramienta eficaz para la reducción del riesgo de inundación. Esta norma ha primado las acciones de ordenación territorial y la elaboración de cartografía oficial de riesgo en los países de la Unión Europea. Esto implicó la adopción de normas ambientales o específicamente hidráulicas, además de la modificación de las normativas del suelo en función de la elaboración de planes de ordenación territorial para el riesgo de inundaciones que obliga esta norma europea. En España, la incorporación de cartografía e informes de riesgos en la escala local ha sido efectiva a partir de la modificación de la Ley estatal del Suelo en 2008, que ha tenido una versión revisada en 2015. El artículo 22 de esta ley señala, explícitamente, que la acreditación de la condición de riesgo de un espacio geográfico está determinada por la elaboración de un mapa de riesgo. De manera que, desde 2008, no existe excusa legal en España para omitir la elaboración de cartografía de riesgo en los planes urbanísticos, bien de nueva factura o bien con la utilización de las cartografías oficiales existentes (SNCZI o cartografías existentes en algunas Comunidades Autónomas). Otra cuestión es la vigilancia que las administraciones local y regional deben llevar para el cumplimiento efectivo de este precepto normativo (Olcina Cantos, 2008). La redacción del artículo 22 de la Ley del Suelo ha sido demasiado laxa. Se habla de "riesgos naturales" sin detallar qué riesgos na- 
turales deben priorizarse y cuáles pueden tener un carácter complementario en cada caso. Lo que ha derivado en la elaboración, en la mayoría de los casos, de mapas de peligrosidad o de riesgo de inundación casi en exclusiva, obviando otros peligros naturales de impronta territorial destacada (deslizamientos, temporales en la costa, etc.).

El componente "territorial" en la reducción del riesgo de inundaciones se ha ido incorporando en normas y planes elaborados por las Comunidades Autónomas que, en algunos casos, han elaborado cartografías de peligrosidad y riesgo de obligada observancia en los procesos de planificación territorial a diferentes escalas. No en todas las regiones se han elaborado normas o planes en este sentido, pero deben destacarse los casos del País Vasco, Navarra, Cataluña, Baleares, Comunidad Valenciana, Andalucía y Canarias. Se trata, por lo demás, de aquellos territorios que han hecho una apuesta por la sostenibilidad como principio de ordenación del territorio, considerando que un principio de sostenibilidad territorial es la reducción del riesgo natural o tecnológico (Elorrieta Sanz et al., 2016). Incluso se han elaborado cartografías oficiales, de obligada consulta en los procesos de planificación de escala subregional o local. Es el caso del Plan de Ordenación de Márgenes de los Ríos y Arroyos del País Vasco (1998 y 1999 y rev. 2013), del Plan de Acción Territorial para el Riesgo de Inundaciones en la Comunidad Valenciana (PATRICOVA 2002 y rev. 2015) o del Plan de Avenidas en cauces urbanos de Andalucía (PCAl, 2002). En estos tres casos, la normativa que acompaña a estos planes de actuación territorial de carácter sectorial llega a limitar usos del suelo en relación con el nivel de riesgo existente en el territorio objeto de actuación.

\section{Cuadro $\mathrm{N}^{\circ} 3$.}

Cartografía de riesgo de inundación existente en España, según escalas administrativas (2020)

\begin{tabular}{|c|l|}
\hline ESCALA DE TRABAJO & CARTOGRAFÍA DE RIESGO DE INUNDACIÓN EXISTENTE \\
\hline ESTATAL & $\begin{array}{l}\text {-Sistema Nacional de Cartografía de Zonas Inundables (SNCZI). Creado } \\
\text { por Directiva Europea 60/2007. }\end{array}$ \\
\hline REGIONAL & $\begin{array}{l}\text {-Cartografía de riesgo de inundación incluida en Planes de Ordenación } \\
\text { Territorial para la reducción del riesgo o Planes de Protección Civil de } \\
\text { obligada observancia en los procesos territoriales (País Vasco, C. Valen- } \\
\text { ciana, Cataluña, Andalucía, Baleares). }\end{array}$ \\
\hline LOCAL & $\begin{array}{l}\text {-Mapas de riesgo elaborados para los Planes Urbanísticos de escala mu- } \\
\text { nicipal (Ley del Suelo 2008, rev. 2015). Cumplimiento desigual y sin cri- } \\
\text { terios uniformes para su realización. }\end{array}$ \\
\hline
\end{tabular}

Fuente: Elaboración propia.

A modo de ejemplo, la Comunidad Valenciana es, en el contexto español, una de las regiones que ha desarrollado normativa y planes de reducción del riesgo natural, especialmente de inundaciones, desde 2000. La aprobación, en 2003, del Plan de Acción Territorial de Prevención de Inundaciones (PATRICOVA), revisado en 2015, ha constituido un hito para la reducción de la ocupación de espacios inundables por los usos urbanos e infraestructuras en este espacio geográfico (Figura $\mathrm{N}^{\circ} 4$ ). No obstante, el ritmo de actuación ha sido lento en relación con la acelerada transformación de suelo experimentada en los primeros años del nuevo siglo. En efecto, entre 2003 y 2012, momento en que se inicia la revisión del PATRICOVA, la superficie total informada referida a planes generales, planes urbanísticos y actuaciones puntuales ha sido de 262.876 ha, lo que supone el $11,3 \%$ de la superficie total de la Comunidad Valenciana. Si se considera únicamente la superficie inundable en esta región, según el PATRICOVA se trataría de 118.194 ha, de las cuales 
se ha informado una superficie de 14.294 ha, equivalente al $12,1 \%$ de la superficie inundable total. A su vez, cabe destacar que el PATRICOVA incorpora una visión integral de riesgo, a través de la combinación de la peligrosidad y vulnerabilidad en la delimitación de las zonas inundables y el establecimiento de su grado de riesgo.

Figura $\mathrm{N}^{\circ} 4$

Mapa de riesgo de inundación. Escala regional. Sector de la cuenca baja del río Júcar, proximidades de la ciudad de Valencia (2020)

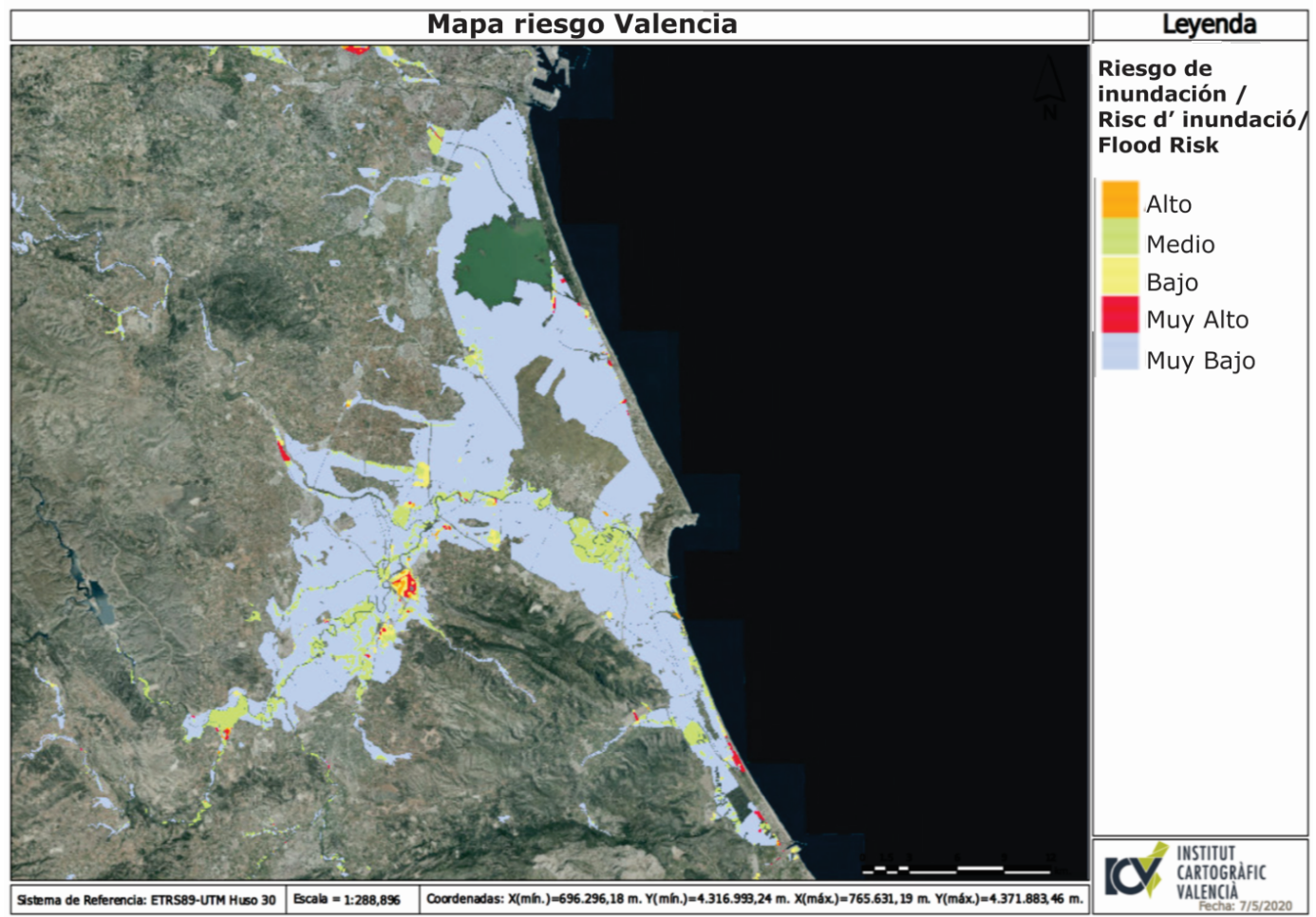

Fuente: PATRICOVA. Gobierno regional de la Comunidad Valenciana. Disponible en:http://politicaterritorial.gva.es/es/web/planificacion-territorial-e-infraestructura-verde/cartografia-del-patricova

En la escala local, a pesar de la obligatoriedad establecida para la elaboración de cartografía de riesgo en la legislación del suelo, la realidad difiere según los municipios. La experiencia ha demostrado que la aplicación del artículo 22.2 (texto refundido de la Ley de Suelo de 2015) no está resultando todo lo completa y ágil que se esperaba. No son muchos los municipios españoles que hayan aprobado su nuevo plan general de ordenación municipal con posterioridad al año 2008 y que incorporen cartografía de riesgo natural precisa y completa, adaptada a los rasgos del medio físico y social de dichos municipios. El informe del Colegio de Geólogos que analiza el grado de cumplimiento de la incorporación de mapas de riesgo en el planeamiento urbano (Mancebo, 2014) manifiesta que de los 54 municipios analizados, sólo ocho (El Prat de Llobregat, Esplugues de Llobregat, San Joan Despí, Martorell, Portugalete, Marbella, Catarroja y El Campello) disponen de cartografía de inundación más allá del mero mapa de peligrosidad hidrológica; esto es, en ellos se han incluido mapas de riesgo geológico, geomorfológico e hídrico (acuíferos), pero no son, 
sin embargo, mapas de riesgo. El resto de la muestra analizada o no disponen de ningún mapa o incorporan tan sólo un mapa de peligrosidad (no de riesgo) de inundaciones.

En una reciente investigación que evalúa el grado de cumplimiento del artículo 22.2 de la Ley del Suelo 2015 en los seis municipios de la provincia de Alicante que han aprobado su Plan de Ordenación Urbana con posterioridad al año 2008, los resultados no dejan margen para el optimismo (Olcina et al., 2018). Allí, la inundación es el peligro natural que merece mayor tratamiento, debido a la existencia del PATRICOVA en la Comunidad Valenciana y a la obligación de su observancia en los procesos territoriales. Otros peligros naturales apenas merecen breves referencias y no se aporta cartografía específica. Sorprende comprobar que la sequía, el otro gran peligro natural de importancia socioeconómica y territorial en este territorio ibérico, no aparece estudiada ni cartografiada en estos casos analizados.

La relación de estas deficiencias analizadas en los casos de estudio indica que, por lo general, este artículo 22.2 se entiende, básicamente, como incorporación de un "mapa de inundaciones" del término municipal que, en esencia, es un mapa de peligrosidad de inundaciones, no de riesgo (Figura $\mathrm{N}^{\circ}$ ). No se contiene cartografía de riesgo sísmico si bien gran parte de la provincia de Alicante se encuentra en zona de moderada o alta peligrosidad (norma sismorresistente, 2002, Plan Especial de Riesgo Sísmico de la Comunidad Valenciana, 2011). Tampoco cartografía de riesgo de erosión, deslizamientos o incluso de incendios forestales, especialmente en municipios de la montaña interior provincial. En ningún caso, a pesar de no estar contemplado como tal en la normativa del suelo, se menciona ni se cartografía en los informes de sostenibilidad ambiental la referencia al cambio climático y sus posibles efectos. Esta ausencia es particularmente notable en municipios litorales con ocupación urbana de primeras líneas de costa.

La publicación de guías oficiales para la elaboración de cartografía de riesgos naturales (Ministerio de Vivienda y Colegio de Geólogos, 2008) o para la reducción de la vulnerabilidad de edificios frente a las inundaciones (MAGRAMA, MINECO y Consorcio de Compensación de Seguros, 2017) constituyen herramientas de trabajo de gran interés para unificar métodos, escalas y sistemas de representación de las áreas de riesgo en la escala local. A ello se ha unido la mejora en la normativa de aguas cuyos preceptos afectan a la planificación territorial y urbana puesto que en España la clasificación de un espacio geográfico como "área inundable" depende, de entrada, de una medida hidráulica (período de retorno de 500 años). El último eslabón importante en este sentido ha sido la promulgación del RD 638/2016, por el que se modifica el Reglamento de Dominio Público Hidráulico y donde se contiene novedades importantes para la consideración y tratamiento del riesgo de inundaciones en la planificación territorial. Destacan el uso de fuentes y métodos hidrológicos, hidráulicos, geomorfológicos, fotográficos, cartográficos e históricos para delimitar el Dominio Público Hidráulico, sus áreas de influencia y las zonas inundables y el hecho de que en las edificaciones en zona de flujo preferente o en zona inundable, el promotor deberá aportar "Declaración de responsabilidad" y "Certificado de inscripción en el Registro de la propiedad". La "zona inundable" (período de retorno de 500 años) pasa a delimitarse además de con criterios hidrológicos, con elementos geomorfológicos e históricos también. El Sistema Nacional de Cartografía de Zonas Inundables, derivado de la adaptación de la Directiva 60/2007 es la referencia cartográfica básica para la elaboración de mapas de riesgo de inundación en la escala local. 
Figura $N^{\circ} 5$

Mapa de inundabilidad -peligrosidad- del municipio de Sant Joan (sector río Seco). Plan General de Ordenación Urbana (2013). Es una trasposición a escala 1:10.000, de la cartografía del PATRICOVA de

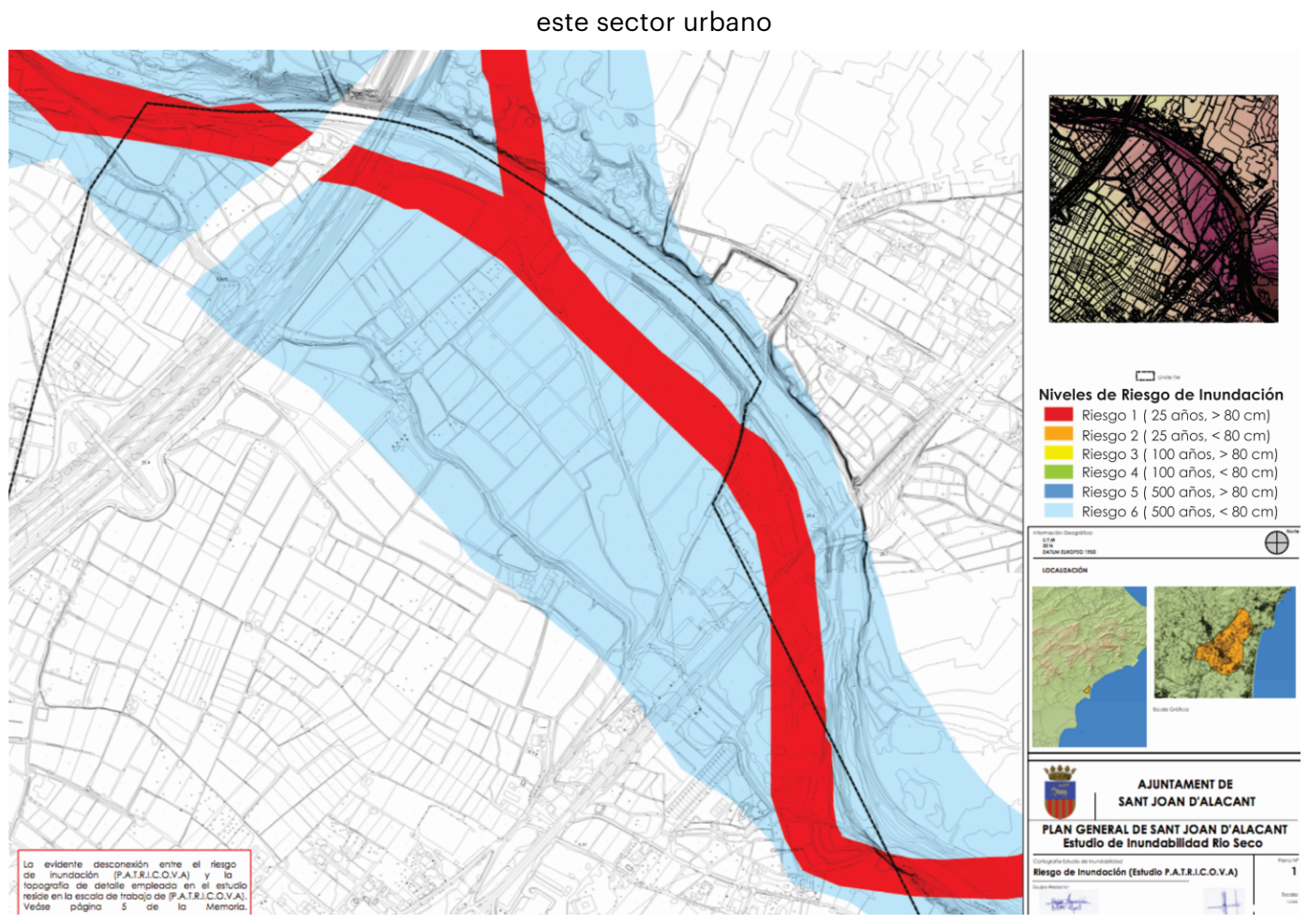

Fuente: PGOU Sant Joan. Disponible en: http://www.santjoandalacant.es/es/urbanismo/pgou-2013

\section{Diferencias en la aplicación de cartografía de riesgo de inundación en la planificación territorial en ciudades de España y Argentina}

Las diferencias encontradas al comparar, entre ambos países, el uso del mapa de riesgo de inundación en procesos de ordenación territorial, abarcan aspectos propios de la elaboración cartográfica y también cuestiones que hacen a su marco de aplicación. El Cuadro $N^{\circ} 4$ sintetiza la comparación en función de las propiedades y las variables de los mapas. Es interesante distinguir diferencias en términos de la relación entre la escala de resolución, es decir, escala de análisis y la escala cartográfica, es decir, escala de representación. En el caso español existen mapas de zonificación de riesgo a escala 1:10.000. Esto permite que mapas elaborados a un nivel de resolución local encuentren correspondencia con el nivel de detalle que brindan las escalas cartográficas grandes. Mientras que en el caso de los mapas de inundación de Argentina, si bien se plantean a resolución local el nivel de detalle espacial que se obtiene de las escalas cartográficas medias (a partir de 1:50.000) puede ser insuficiente. Cabe destacar, por otra parte, que la inclusión de la exposición y de las condiciones de vulnerabilidad en la delimitación de niveles de riesgo de inundación está más consolidada en el procedimiento de España que en Argentina, donde prima aún la utilización de cotas hidrométricas. 


\section{Cuadro N4.}

Aplicación de cartografía de riesgo de inundación en la planificación territorial en ciudades

de España y Argentina

\begin{tabular}{|l|l|l|}
\hline & \multicolumn{1}{|c|}{ ARGENTINA } & \multicolumn{1}{c|}{ ESPAÑA } \\
\hline $\begin{array}{l}\text { ESCALA DE } \\
\text { RESOLUCIÓN / ESCALA } \\
\text { CARTOGRÁFICA }\end{array}$ & $\begin{array}{l}\text { Escala de resolución local, } \\
\text { pero escala cartográfica me- } \\
\text { dia (1:50.000) }\end{array}$ & $\begin{array}{l}\text { Escala de resolución local que en- } \\
\text { cuentra correspondencia con escala } \\
\text { cartográfica grande (1:10.000). }\end{array}$ \\
\hline $\begin{array}{l}\text { VISIÓN DEL MAPA DE } \\
\text { RIESGO }\end{array}$ & $\begin{array}{l}\text { Documento técnico para la la } \\
\text { adopción de medidas estruc- } \\
\text { turales }\end{array}$ & $\begin{array}{l}\text { Documento operativo para la planifi- } \\
\text { cación territorial }\end{array}$ \\
\hline $\begin{array}{l}\text { VARIABLES } \\
\text { CARTOGRAFIADAS }\end{array}$ & $\begin{array}{l}\text { Delimitación de restricciones } \\
\text { en función de alturas hidromé- } \\
\text { tricas y períodos de retorno. }\end{array}$ & $\begin{array}{l}\text { Niveles de riesgo procedentes del } \\
\text { cruce entre peligrosidad (períodos de } \\
\text { recurrencia) y vulnerabilidad (pobla- } \\
\text { ción y actividades económicas) }\end{array}$ \\
\hline MARCO NORMATIVO & $\begin{array}{l}\text { Ordenanzas que consideran la la } \\
\text { delimitación de línea de ribera } \\
\text { a cargo de instituciones pro- } \\
\text { vinciales de agua. }\end{array}$ & $\begin{array}{l}\text { Planes municipales que se adaptan a } \\
\text { lo contenido en Leyes Autonomicas, } \\
\text { que a su vez recogen lo contenido en } \\
\text { la Ley estatal del Suelo. A escala euro- } \\
\text { pea: la Directiva 60/2007. }\end{array}$ \\
\hline
\end{tabular}

Fuente: Elaboración propia.

Por otra parte, del análisis del marco legal que define la aplicación de los mapas de riesgo (Cuadro $\mathrm{N}^{\circ}$ ) se destaca, en el caso español, la existencia de normativa del suelo de escala estatal que impulsa la inclusión, por parte de los municipios, de cartografía de riesgo en los documentos de planeamiento urbanístico. Si bien ello no garantiza el cumplimiento pleno de los requisitos técnicos de los mapas de riesgo y existen aún aspectos de la peligrosidad y vulnerabilidad que quedan a criterio de los autores de los mapas. Es necesario, en definitiva, un mayor control por parte de las administraciones competentes (escala autonómica) del cumplimiento de este precepto legal que obliga a elaborar mapas de riesgo y no sólo de peligrosidad. E igualmente, conviene la promulgación de un decreto legal que explique los criterios básicos de obligado cumplimiento que deben incluir estos mapas de riesgo. En tanto que en el caso argentino, se identificó la consideración integral del riesgo en planes y también en propuestas metodológicas impulsadas en el marco del SINAGIR. Sin embargo, no existe una correspondencia por parte de la normativa destinada a regular los procesos de habilitación de áreas para urbanización. Sino que para ello se requieren estudios de factibilidad hídrica cuyo objetivo principal es indicar las vías de evacuación del agua. Asimismo, la figura de línea de ribera tiene valor legal en la delimitación de zonas de riesgo hídrico. 
Cuadro $\mathrm{N}^{\circ} 5$.

Comparación de la incorporación de la cartografía de inundabilidad en los procesos de ordenación del territorio en Argentina y España

\begin{tabular}{|l|l|l|}
\hline & \multicolumn{1}{|c|}{ ARGENTINA } & \multicolumn{1}{c|}{ ESPAÑA } \\
\hline LEGISLACIÓN & $\begin{array}{l}\text { No existe legislación que obligue } \\
\text { la implementación de cartografía } \\
\text { para acreditar niveles de riesgo } \\
\text { de inundación. }\end{array}$ & $\begin{array}{l}\text { Ley del Suelo } 2015 \text { y normativas } \\
\text { del suelo y ordenación del terri- } \\
\text { torio de las Comunidades Autó- } \\
\text { nomas. }\end{array}$ \\
\hline $\begin{array}{l}\text { CUMPLIMENTO DE } \\
\text { NORMA }\end{array}$ & $\begin{array}{l}\text { Laxo. Existen acotados de estu- } \\
\text { dios de factibilidad hídrica que } \\
\text { vinculan el riesgo de inundación } \\
\text { con la línea de ribera. }\end{array}$ & $\begin{array}{l}\text { Laxo. Se permiten cartografías } \\
\text { que no cumplen los mínimos ne- } \\
\text { cesarios en un mapa de riesgo. } \\
\text { incluso planes que no contienen } \\
\text { mapas de riesgo. }\end{array}$ \\
\hline $\begin{array}{l}\text { CALIDAD DE LAS } \\
\text { CARTOGRAFÍAS }\end{array}$ & $\begin{array}{l}\text { Mapas de peligrosidad. Se exclu- } \\
\text { yen elementos de vulnerabilidad. }\end{array}$ & $\begin{array}{l}\text { Mapas de peligrosidad+vulnera- } \\
\text { bilidad (criterios sin regular; en } \\
\text { función del autor/a de los mapas) }\end{array}$ \\
\hline $\begin{array}{l}\text { CONSIDERACIÓN } \\
\text { INTEGRAL DEL RIESGO }\end{array}$ & $\begin{array}{l}\text { Se identifica en planes y propues- } \\
\text { tas. No existe un marco normati- } \\
\text { vo que guíe su implementación. }\end{array}$ & $\begin{array}{l}\text { Recogida en la normativa. Inexis- } \\
\text { tente en la práctica en la mayoría } \\
\text { de los casos. }\end{array}$ \\
\hline
\end{tabular}

Fuente: Elaboración propia.

\section{Discusión}

Del análisis en ambos países se comprueba que la existencia de una normativa del suelo, de escala estatal y con efectos en las escalas regionales y locales, es un factor fundamental en la incorporación de cartografía de riesgo en los procesos de planificación territorial (Olcina, 2018). Esto explica en gran parte la diferencia que se presenta entre ambos países en cuanto a la implementación de documentos cartográficos para ordenar los usos del suelo en áreas con riesgo de inundación. También se plantean diferencias en la legislación de aguas. En España, los cambios introducidos en el proceso de determinación de perímetros de protección y salvaguarda del dominio público hidráulico contribuyeron con la integración de la normativa hidráulica y territorial en función de la reducción del riesgo de inundaciones. Mientras que en Argentina se delimita el peligro hídrico a través de la línea de ribera, figura cuyo objetivo principal es el deslinde del espacio público adyacente a un curso de agua. Asimismo, los gobiernos provinciales encargados de su demarcación presentan diferencias en cuanto a los procedimientos para su definición y las restricciones al dominio privado que se derivan de la misma (Zapperi, 2018).

Los datos sobre la aplicación de las normativas de ordenación del territorio de Argentina y España en la disminución del riego de inundación son interesantes pero descorazonadores por el ritmo lento en que se consigue reservar suelo con riesgo para fines no residenciales o infraestructurales. Mientras que en España el criterio de elaboración cartográfica busca llegar a un documento operativo para la planificación territorial, en Argentina aún prima la visión técnica del mapa de riesgo. Si bien se han identificado iniciativas que incorporan el análisis de la vulnerabilidad y grado de exposición, las mismas sustentan procesos de alerta y manejo de la emergencia. 
Es de destacar que a pesar de la trayectoria argentina en inundaciones urbanas y el aumento de su frecuencia como de casos inéditos, se identificó solo el caso del AMGR para ejemplificar la aplicación de mapas de riesgo hídrico en la zonificación urbana. Existen antecedentes en otras ciudades con restricción de usos en áreas inundables, pero se identifica un importante vacío en cuanto a la utilización de cartografía. Sin embargo, esto puede significar una oportunidad pues las iniciativas en curso como las venideras encuentran en la actualidad un paradigma de riesgo que busca definir áreas de peligro y también facilitar la articulación de las vulnerabilidades que intervienen en la construcción de las condiciones de riesgo.

En España, por su parte, la implementación de cartografía de riesgo de inundación en la planificación territorial es un proceso que comenzó con la Ley del Suelo del año 2008 y su modificación en 2015. De esta manera, los municipios, en la fase de elaboración y aprobación inicial de los planes urbanísticos y los organismos regionales con competencias en urbanismo y ordenación territorial deberán extremar la vigilancia en el cumplimiento de la inclusión en los documentos de planeamiento urbanístico de cartografía e informe de riesgo. Tanto por la responsabilidad civil o penal que conlleva el posible desarrollo de un evento natural extremo con efectos no deseados.

Por último, cabe mencionar la coordinación de escalas institucionales que propia el marco para el análisis del riesgo a diferentes escalas cartográficas. Ello se refleja en los mapas obtenidos del Sistema Nacional de Cartografía de Zonas Inundables (SNCZI) de España. Precisamente, eventos como las inundaciones requieren un abordaje a diferentes niveles espaciales siendo lo deseable la integración de los núcleos urbanos en las cuencas hidrográficas. Al mismo tiempo que el tratamiento de los aspectos de la vulnerabilidad y de la exposición exigen un elevado nivel de detalle que puede obtenerse a través de escalas cartográficas grandes (1:10.000 o mayores). En la Argentina, se identifica un trabajo de integración en el ámbito de la Red de Organismos Científico-Técnicos para la Gestión Integral del Riesgo (GIRCYT). Sin embargo, sus esfuerzos se orientan a fortalecer las condiciones de interoperabilidad y visualización de la información geoespacial vinculada con la gestión de la emergencia. Es por ello que podría ser una alternativa que sobre la base de estos antecedentes se construyan las estructuras de información que puedan sustentar a futuro la construcción de mapas de riesgo para la elaboración de planes y diagnósticos orientados a la habilitación de nuevas áreas urbanizables como el tratamiento de las ya existentes.

\section{Conclusión}

No hay soluciones únicas ante un peligro natural. La naturaleza tiene su comportamiento, a veces extremo, y corresponde al ser humano conocer lo mejor posible dicha dinámica para adaptar sus actuaciones sobre el espacio geográfico. La mejora en los conocimientos científicos y niveles de técnica permite acercarse o incluso rebasar los límites que la naturaleza asigna a las actividades y asentamientos sobre el territorio. Esta condición de riesgo asumido plantea la necesidad de reconocer las consecuencias catastróficas que pudieran generarse a partir de un episodio extremo de crecida fluvial. Hasta hace pocos años, la confianza residía plenamente sobre las medidas estructurales. Si bien han sido eficaces para disminuir la mortalidad ante estos episodios no ocurre lo mismo con la exposición y la vulnerabilidad que, por el contrario, se ha incrementado. 
Puesto que este tipo de medidas se ha implementado en ambos países y que merced a las normativas ambientales la tramitación y aprobación de obras de infraestructura hidráulica se ha complejizado, la ordenación del territorio será a medio y largo plazo el procedimiento más eficaz para disminuir el riesgo natural. Junto a ello la educación para el riesgo es una medida esencial y con potencialidad de desarrollo en ambos países. Sirve de ejemplo el modelo francés que impone planes de prevención de riesgos (PPR) a escala local, donde el máximo nivel de riesgo de inundación supone restricciones de usos futuros del suelo en las áreas no actuadas y también el desalojo de espacios ya urbanizados a partir de la calificación de "zonas de sacrificio". Urge además una aplicación disciplinada de la normativa ambiental y urbanística y la incorporación de cartografía de riesgo en los procesos de asignación de nuevos usos en el suelo, especialmente en la escala local.

De las lecciones aprendidas en el análisis sobre la incorporación de los mapas de riesgo natural en los procesos de ordenación del territorio en la Argentina y España se destaca como hecho fundamental la existencia de una normativa de escala estatal, con implicaciones en las escalas inferiores (regional y local) que obligue a la elaboración de este tipo de cartografía en los documentos de planificación espacial. Si se deja a la libre voluntad de las administraciones competentes en materia de ordenación territorial, la realidad suele ser el incumplimiento de este procedimiento y por lo tanto la no existencia de unos mapas oficiales de acreditación del grado de riesgo. Este aspecto es más notable en la Argentina que carece de una exigencia legal de este tipo, que existe en España, por imposición de la UE (Directiva 60/2007), desde 2015.

Este hecho requiere voluntad firme de control de la incorporación de mapas de riesgo en la ordenación del territorio por parte de las administraciones que deben aprobar, en última instancia, estos documentos de planeamiento urbano y territorial. Este aspecto es un elemento de mejora en ambos países, puesto que, en España, con un nivel de desarrollo normativo mayor en este tema, sigue presentando ejemplos de ocupación de zonas inundables debido a la mala calidad de los mapas de riesgo elaborados y a la falta de determinación por parte de las administraciones (regionales y locales) que deben aprobar los documentos de planificación territorial y urbanística.

Otro aspecto a destacar es la necesidad de incorporar una visión integral en el análisis de riesgo y su plasmación cartográfica. Los mapas a incluir en un plan de ordenación territorial no pueden ser, únicamente, mapas de zonas afectadas por una inundación o mapas de peligrosidad. Deben incorporarse los aspectos sociales, económicos y patrimoniales para elaborar una radiografía cartográfica exhaustiva del riesgo en un espacio geográfico que está ocupado o que se pretende ocupar con usos de forma permanente. Este aspecto es muy mejorable en ambos países puesto que, salvo excepciones, se ha entendido el riesgo de inundaciones únicamente como peligrosidad ante las inundaciones en las cartografías que se incorpora a los planes de planificación territorial.

La ordenación del territorio, con criterios de reducción de los efectos del cambio climático y de los peligros naturales, es una estrategia positiva de adaptación del espacio geográfico a las consecuencias de estos dos procesos físicos, pero con una incentivación de su grado de riesgo por parte del ser humano. El cumplimiento de los acuerdos internacionales de lucha contra el cambio climático (Acuerdo de París) y de los Objetivos de Desarrollo Sostenible, en lo que respecta a la conservación y gestión sostenible de los territorios y de adaptación al cambio climático, 
tienen en la infraestructura verde un procedimiento de intervención en la planificación territorial respetuosa con el medio ambiente, con sus cambios previstos por el cambio climático y con su funcionamiento a veces extremo.

\section{Referencias}

ALCALÁ, L. \& RUS, M. F. Áreas Urbanas Deficitarias Críticas en Territorios con Riesgo Hídrico. Análisis comparado de situaciones en las ciudades de Resistencia y Corrientes. En: Centro de Investigaciones Urbanas y Territoriales (Ed.). Seminario Internacional de Ordenamiento Territorial. Mendoza: UNCuyo, 2017. Disponible en internet: https://bdigital.uncuyo.edu.ar/objetos_digitales/10840/e1alcala-rus.pdf

AYALA-CARCEDO, F. J. La ordenación del territorio en la prevención de catástrofes naturales y tecnológicas. Bases para un procedimiento técnico-administrativo de evaluación de riesgos para la población. Boletín de la Asociación de Geógrafos Españoles, 2000, № 30, p. 37-49.

BARROS, V. R.; BONINSEGNA, J. A.; CAMILLONI, I. A.; CHIDIAK, M.; MAGRÍN, G. O. \& RUSTICUCCI, M. Climate change in Argentina: trends, projections, impacts and adaptation. Wiley Interdisciplinary Reviews: Climate Chang. 2015, Vol. 6, № 2, p. 151-169. https://doi.org/10.1002/wcc.316

BARTON, J. \& IRARRÁZABAL, F. Adaptación al cambio climático y gestión de riesgos naturales: buscando síntesis en la planificación urbana. Revista de Geografía de Norte Grande, 2016, N 63 , p. 87-110. http://dx.doi.org/10.4067/S0718-34022016000100006

BERTONI, J. C. Urbanización y drenaje urbano en Argentina. En Bertoni, J. C. (coord.). Inundaciones urbanas en Argentina. Córdoba: Instituto Nacional del Agua, 2004. Disponible en internet: http://repo.floodalliance.net/jspui/handle/44111/1822

BORUP, M.; BROWN, N.; KONRAD, K. \& VAN LENTE, H. The sociology of expectations in science and technology. Technology Analysis \& Strategic Management, 2006, Vol. 18, N 3-4, p. 285-298. http://dx.doi.org/10.1080/09537320600777002

CALVO GARCÍA-TORNEL, F. Sociedades y territorios en riesgo. Barcelona: Ediciones del Serbal, 2001.

CARDONA, O. D. La noción de riesgo desde la perspectiva de los desastres. En: Cardona, O.; Instituto de Estudios Ambientales (IDEA) (coords.). Sistema de Indicadores para la Gestión del Riesgo de Desastre: Programa para América Latina y el Caribe; Informe Técnico Principal. Manizales, Banco Interamericano de Desarrollo, Universidad Nacional de Colombia-Instituto de Estudios Ambientales, 2003, p. 5-16.

CONSORCIO DE COMPENSACIÓN DE SEGUROS. Guía para la reducción de la vulnerabilidad de los edificios frente a las inundaciones. Madrid: MAGRAMA, MINECO y Consorcio de Compensación de Seguros, 2017. 
DE MATTOS, C. A. Globalización y metamorfosis metropolitana en América Latina: de la ciudad a lo urbano generalizado. Revista de Geografía Norte Grande, 2010, № 47, p.81-104. https://scielo. conicyt.cl/pdf/rgeong/n47/art05.pdf

DE ROO, G. \& PORTER, G. Fuzzy planning the role of actors in a fuzzy governance environment. Aldershot: Ashgate, 2007.

ELORRIETA SANZ, B.; OLCINA CANTOS, J. \& SÁNCHEZ AGUILERA, Ma D. La sosteniblidad en la planificación territorial de escala regional en España: estudio de casos. Cuadernos Geográficos, 2016, Vol. 55, №1, p. 149-175.

GIL-GUIRADO, S.; PÉREZ, A. \& BARRIENDOS, M. Increasing vulnerability to flooding in the southern Spanish Mediterranean coast (1960-2013). En: Hydrological Extreme events in historic and prehistoric times. Bonn: Department of Geography, Rheinische Friedrich-Wilhelms-Universitaet, 2014.

GONZÁLEZ GARCÍA, J.L. (Ed.). Mapas de riesgos naturales en la ordenación urbanística. Madrid: Ilustre Colegio Oficial de Geólogos, 2009.

GONZÁLEZ, S. Las inundaciones en Argentina: ¿manejo o gestión? En: PANGRACIO, A.; NÁPOLI, A. \& NORDENSTAHL, S. (eds.). Informe Ambiental 10 años. 2018, p. 111-127. Disponible en internet: https://farn.org.ar/wp-content/uploads/2019/07/IAF-2018-1.5.pdf

HOOIJER, A.; KLIJN, F.; PEDROLI, G. B. M. \& VAN OS, A. G. Towards sustainable flood risk management in the Rhine and Meuse river basins: synopsis of the findings of IRMA SPONGE. River research and applications, 2004, Vol. 20, № 3, p. 343-357. https://onlinelibrary.wiley.com/doi/ abs/10.1002/rra.781

HOUSTON, D.; WERRITY, A.; BASSETT, D.; GEDDES, A.; HOOLACHAN, A. \& MCMILLAN, M. Pluvial (rain-related) flooding in urban areas: the invisible hazard. Project Report. Reino Unido: Joseph Rowntree Foundation, 2011. Disponible en internet en: https://www.jrf.org.uk/report/pluvial-rain-related-flooding-urban-areas-invisible-hazard

JRC. Atlas of the Human Planet 2017. Global Exposure to Natural Hazards. European Commission. DG Join Research Center, 2017.

KOKS, E.; JONGMAN, B.; HUSBY, T. \& BOTZEN, W. J. Combining hazard, exposure and social vulnerability to provide lessons for flood risk management. Environmental science \& policy, 2015, Vol. 47, https://doi.org/10.1016/j.envsci.2014.10.013

MANCEBO C. Análisis del cumplimiento de obligación del Mapa de Riesgos Naturales en la Ley 8/2007, del Suelo. Madrid: Ilustre Colegio de Geólogos. Universidad Complutense de Madrid, 2014.

MERZ, B.; HALL, J.; DISSE, M. \& SCHUMANN, A. Fluvial flood risk management in a changing world. Natural Hazards and Earth System Sciences, 2010, Vol. 10, p. 509-527. 
MINISTERIO DE PLANIFICACIÓN FEDERAL, INVERSIÓN PÚBLICA Y SERVICIOS. Plan Estratégico Territorial Avance II: Argentina Urbana. Ciudad Autónoma de Buenos Aires: Ministerio de Planificación Federal, Inversión Pública y Servicios, 2011.

MINISTERIO DE SEGURIDAD DE LA NACIÓN. Manual para la elaboración de mapas de riesgo. Ciudad Autónoma de Buenos Aires: Programa Naciones Unidas para el Desarrollo PNUD, 2017.

MINISTERIO DE VIVIENDA Y COLEGIO OFICIAL DE GEÓLOGOS. Riesgos Naturales. Guía Metodológica para la elaboración de cartografías en España. Madrid: Colegio Oficial de Geólogos, 2008.

OBSERVATORIO DE LA SOSTENIBILIDAD. Población en riesgo de inundación en España en la franja de los primeros 10 kilómetros de costa. Madrid: Observatorio de la Sostenibilidad, Escuela de $\mathrm{Ne}$ gocios de Seguros y Consejo General de los Colegios de Mediadores de Seguros, 2019. (Consulta: 5 de julio 2020). http://www.mediadoresdeseguros.com/cms/archivo/INFORME_INUNDACIONES_ COSTA_2019_v12.pdf

OLCINA CANTOS, J. Cambios en la consideración territorial, conceptual y de método de los riesgos naturales. Scripta Nova. Revista Electrónica de Geografía y Ciencias Sociales, 2008, Vol. 12, № 270. http://www.ub.es/geocrit/sn/sn-270/sn-270-24.htm

OLCINA CANTOS, J. Hacia una ordenación sostenible de los territorios de riesgo en Europa. En: FARINÓS J.; ROMERO J. \& SALOM J. (eds.). Cohesión e inteligencia territorial. Dinámicas y procesos para una mejor planificación y toma de decisiones, Valencia: Publicaciones de la Universitat de Valencia, 2009, p.153-182.

OLCINA CANTOS, J. ¿Es la ordenación del territorio una herramienta eficaz contra el riesgo de inundaciones en España? En: CONDE ANTEQUERA, J; GARRIDO MANRIQUE, J, NAVARRO ORTEGA, A. (coords.); ARANA GARCÍA, E. (dir.). Riesgos naturales y derecho: una perspectiva interdisciplinar. Madrid: Dykinson, 2018, p. 63-82.

OLCINA CANTOS, J. \& DÍEZ-HERRERO, A. Cartografía de inundaciones en España, Estudios Geográficos, 2017, Vol. 78, No 282, p. 283-315.

OLCINA J.; SAURÍ D.; HERNÁNDEZ M. \& RIBAS A. Flood policy in Spain: a review for the period 19832013, Disaster Prevention and Management: an International Journal, 2016, Vol. 25, No 1, p. 41-58.

OLCINA, J.; MOROTE; A. \& HÉRNANDEZ, M. Evaluación de los riesgos naturales en las políticas de ordenación urbana de los municipios de la provincia de Alicante. Legislación y cartografía de riesgo. Cuadernos Geográficos. 2018, Vol. 57, №3, p. 152-176.

OLLERO, A. Un necesario cambio de visión y de estrategia en la gestión de las inundaciones. Tecnoaqua, $2015, N^{\circ} 12$, p. 122-124.

PENNING-ROWSELL, E. C. \& BECKER, M. (eds.). Flood Risk Management: Global Case Studies of Governance, Policy and Communities. Londres: Routledge, 2019. 
PERLES ROSELLÓ, M. J. \& CANTARERO PRADOS, F. Problemas y retos en el análisis de los riesgo múltiples del territorio: propuestas metodológicas para la elaboración de cartografías multi-peligros. Boletín de la Asociación de Geógrafos Españoles, 2010, №52, p. 245-271.

PERLES ROSELLÓ, M. J.; OLCINA CANTOS, J. \& MÉRIDA RODRÍGUEZ, M. Balance de las políticas de gestión del riesgo de inundaciones en España: de las acciones estructurales a la ordenación territorial. Ciudad y Territorio Estudios Territoriales (CYTET), 2018, Vol. 50, № 197, p. 417-438.

RAN, J. \& NEDOVIC-BUDIC, Z. Integrating Flood Risk Management and Spatial Planning: Legislation, Policy, and Development Practice. Journal of Urban Planning and Development, 2017, Vol. 143, № 3. https://doi.org/10.1061/(ASCE)UP.1943-5444.0000376

RIBAS, A. \& SAURÍ, D. De la geografía de los riesgos a las geografías de la vulnerabilidad. En: NOGUÉ, J. \& ROMERO, J. (eds.), Las otras geografías. Valencia: Tirant lo Blanc, 2006, p. 285-300.

RIBAS, A.; OLCINA, J. \& SAURI, D. More exposed but also more vulnerable? Climate change, high intensity precipitation events and flooding in Mediterranean Spain. Disaster Prevention and Management: An International Journal, 2020, Vol. 29, N³, p. 229-248.

RÍOS, D. \& NATENZON, C. (eds.). Riesgos, catástrofes y vulnerabilidades. Aporte des- de la geografía y otras ciencias sociales para casos argentinos. Ciudad Autónoma de Buenos Aires: Ediciones Imago Mundi, 2015.

ROHRMANN, H. \& SCHALLER, O. Experiencias de 20 años en gestión de línea de ribera y zonificación de riesgo hídrico, Resistencia-Chaco. En: Seminario Taller Línea de Ribera y Riesgo Hídrico. La Plata: FAU-UNLP, 2016.

ROJAS, O.; MARDONES, M.; ROJAS, C.; MARTÍNEZ, C. \& FLORES, L. Urban growth and flood disasters in the coastal river basin of south-central Chile (1943-2011). Sustainability, 2017, Vol. 2, № 9. https://www.mdpi.com/2071-1050/9/2/195

SERRA-LLOBET A.; CONRAD E. \& SCHAEFER K. Governing for Integrated Water and Flood Risk Management: Comparing Top-Down and Bottom-Up Approaches in Spain and California, Water, 2016, No 8, p. 445-467.

SWISS RE. Staying afloat. Flood Risk in Argentina. 2016. Disponible en internet en: https://reliefweb.int/sites/reliefweb.int/files/resources/Swiss_Re_Argentina_Flood_Risk_Publ_long.PDF

WHITE, G. F.; KATES, R. W. \& BURTON, I. Knowing better and losing even more: the use of knowledge in hazards management. Global Environmental Change, 2001, Vol. 3, No 3. https://www.tandfonline.com/doi/abs/10.3763/ehaz.2001.0308

VIAND, J. \& GONZÁLEZ, S. Crear riesgo, ocultar riesgo: gestión de inundaciones y política urbana en dos ciudades argentinas. En: Primer Encuentro de Investigadores en Formación de Recursos Hídricos. Ezeiza: Instituto Nacional del Agua, 2012. 
